\title{
A Study on The Development of Automatic Design Alternatives Generation Technology Used in the Early Stages of Architectural Design
}

\author{
Yun-Gil Lee ${ }^{1}$ \\ ${ }^{1}$ Associate Professor, Department of Architecture, Hoseo University, Republic of Korea, \\ yglee@hoseo.edu
}

\begin{abstract}
Design automation research, which has been sluggish due to recent advances in computer technology, is becoming a trend. It has also been that the difficult and complex aspects of architectural design require the introduction of artificial intelligence (AI). In other words, we found that the adoption of AI allows us to minimize unnecessary effort and cost and lead to more optimized design plans. However, since most of these studies aim to increase the productivity of architecture, it can be said that these studies are not consistent with the production of more creative results, which is the ultimate goal of architectural design. In addition, because most of the existing technologies related to $\mathrm{AI}$ in the field of architecture design are the production automation technologies for the final stage of architectural design process, so there is a limitation in that design automation is a technology for only fragmentary parts of architectural design. This study is aimed to provide the solution of what the existing design automation studies have overlooked. In other words, it aims to develop a design activation technology that is introduced at the beginning of the design process, thereby differing from the automation technology introduced in the existing design process. As a result, at the beginning of the design stage, architects can quickly access more diverse alternatives, judge them broadly, and provide a computational environment in which they can derive the best plan. Furthermore, this study explored the possibility of introducing artificial intelligence in the early stages of design through technology development. It was confirmed that the introduction of artificial intelligence in the early stages of design through the developed prototype system enables the reproduction of creative results based on traditional architectural design methods. In this paper, the theoretical background and strategy of the introduction of design automation technology for the production of creative results are described, and the results of technology development are introduced. FPG(Floor Plan Generater) introduced in the end of this paper is a kind of automatic design altermatives generation technology, deveploed in this reseach.
\end{abstract}

Keywords: Design Automation, Artificial Intelligence, Evaluation, Architectural Design

\section{Introduction}

\subsection{Background}

The introduction and spread of artificial intelligence (AI) is a phenomenon occurring in all fields of society, and the field of architecture is no exception. Recently, through many researchers and companies, theoretical research and technology development using AI in the fields of architectural design, construction, and management have been conducted. In the field of architectural design,

Received: October 25, 2020; 1st Review Result: December 14, 2020; 2nd Review Result: January 28, 2021 Accepted: February 26, 2021 
similar research has been conducted for years under the name of design automation. However, the introduction of $\mathrm{AI}$ in the architectural field is relatively slow-moving compared to other fields due to the specificity of the construction industry. In other words, architecture is a structure that is difficult to follow regarding modern factory-based industrial methods of the mass production of small items. In particular, architectural design is difficult to formalize electronically because different products must be created for different situations each time. The number of cases to be solved by architects is difficult to formulate with a specific model, and it is not easy to generalize because it must be applied differently for each site. In addition, it is true that architectural design is not agile in the introduction of advanced external technologies, as it prefers to proceed in a traditional and customary manner, such as through the use of an architect's knowledge, experience, and building laws[1].

Design automation research, which has been sluggish due to recent advances in computer technology, is accelerating. It has also been recognized that the difficult and complex aspects of architectural design require the introduction of artificial intelligence (AI). In other words, we found that the adoption of AI allows us to minimize unnecessary effort and cost and lead to more optimized design plans. However, since most of these studies aim to increase the productivity of architecture, it can be said that these studies are not consistent with the production of more creative results, which is the ultimate goal of architectural design. In addition, because most of the existing technologies related to $\mathrm{AI}$ in the field of architecture design are the production automation technologies for the final stage of architectural design process, so there is a limitation in that design automation is a technology for only fragmentary parts of architectural design[2][3].

\subsection{Purpose \& Methods}

This study explored the possibility of introducing artificial intelligence in the early stages of design through technology development. This research offers a solution to what the current design automation reports have ignored. In other words, it seeks to establish a design activation technology that is implemented at the outset of the design process and therefore varies from the automation technology introduced in the present design process. As a result, at the outset of the design stage, developers are able to access more easily. In this paper, the theoretical history and plan for the implementation of design automation technologies for the creation of innovative outcomes are identified and the results of technical progress are discussed. FPG(Floor Plan Generator) proposed at the end of this paper is a form of automated design alternative generation technology built in this report.

The research method of this study focused on theoretical investigation and development. Theoretical research derives a development strategy through the analysis of the architectural design process and typical design methodology in the early stages of design. A prototype system was developed by deriving related technologies to realize the derived development strategies and applying them. Through the developed prototype system, the possibility of introducing artificial intelligence in the early stages of architectural design was tested.

\section{Architectural Design and Artificial Intelligence}

\subsection{History of Architectural Design Automation}

If you look at the discourse of design automation in the field of architectural design in the past, it will be reasonable to look at Christopher Alexander's pattern language as the beginning. [Fig. 1] presents a conceptual diagram of pattern language, which presents the hidden standardized features of an architectural space. Furthermore, he suggested the elements that make up the surrounding environment in architectural space design and how to properly organize them. It was criticized that it 
was impossible to mathematically simplify or generalize the creative and complex process of design, but it is meaningful that it suggested the possibility of design automation[4].

In addition, as an architectural designer, Peter Eisenman studied the creation and transformation of various alternatives in his house design process and presented a conceptual vision for design automation. [Fig 2] schematically shows Eisenman's house design process, which can be said to use structuralist characteristics in architectural design. In other words, the process of thinking was applied to the design principle, drawing attention from Avram Noam Chomsky's Transformational Generative Grammar. In the House X project, the plan was specified by dividing the conceptual stage and the realization stage, which is very similar to the process of creation and review of an architect, but it is more systematic, which is in line with the theoretical part of design automation. Huh et al. (1999) said that Eisenman's design process realized that as the problem became visible and specific directions became possible, the architectural theme was developed not only as a temporary but a sustainable theme in the realm of personal intuition. This can be said to predict the possibility and usefulness of the tool to support this thinking process[5].

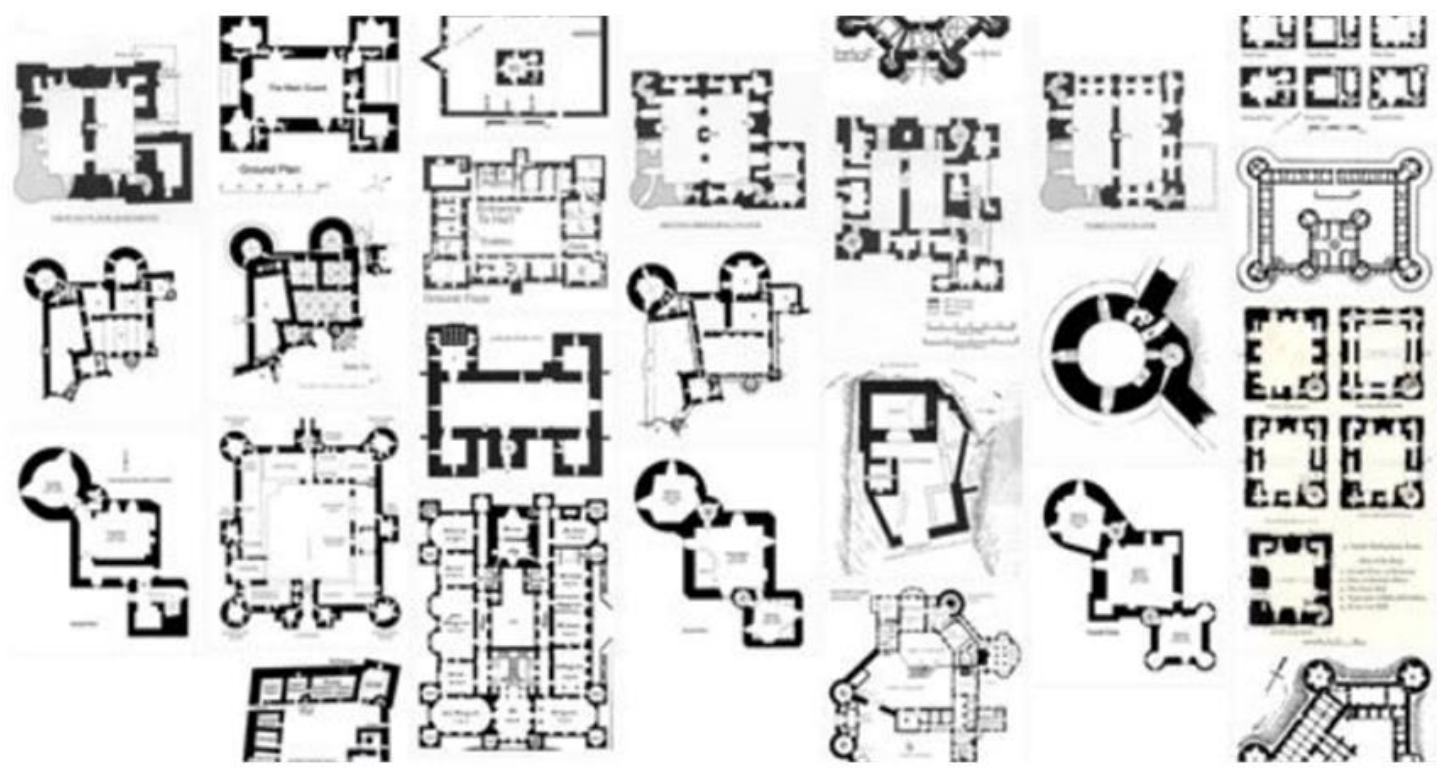

[Fig. 1] Christopher Alexander's Pattern Language

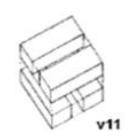

v11
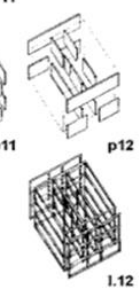
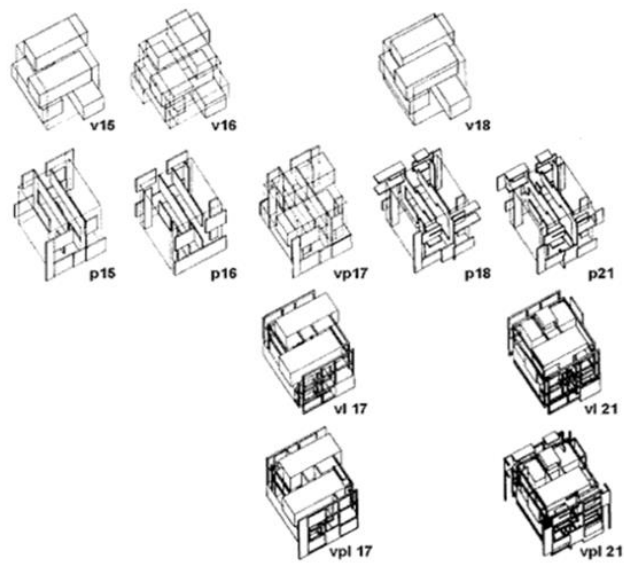

[Fig. 2] Peter Eisenman's House Design Methodology
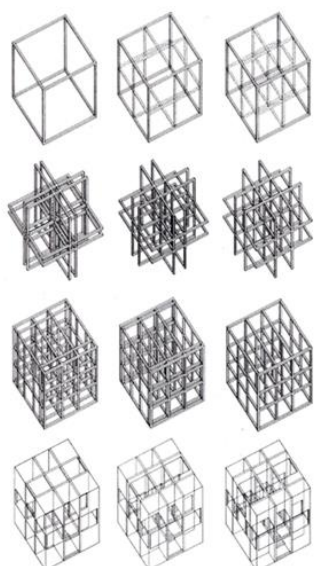
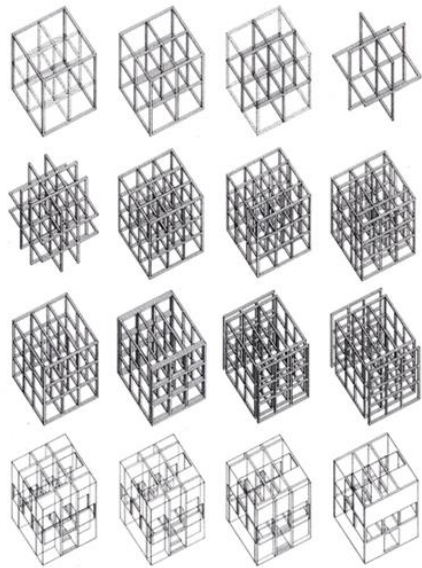


\subsection{Architectural Design Process and Artifical Intelligence}

The architectural design process can vary depending on the individual architect's ability and disposition. It can also be affected by the nature and size of the project. John Archea describes the various architectural design processes as the problem-solving approach and the puzzle-making approach. In the problem-solving approach, the main direction of the design is solving a derived problem. As a universal form of modern architecture design methodology, we propose a design form focusing on architectural solutions (or architecturalization). The puzzle-making approach is the main direction of the design, exploration, and discovery of new things. It is a form of architectural design methodology in the modern atypical form. The exploration and selection of new forms is given priority, and architectural solutions (or architecturalization) follow[6].

Based on the two proposed architectural design processes, the method of introducing AI can be predicted. In the design process, based on the problem-solving approach, AI will be helpful if it performs the task of a tool that supports problem-solving. In other words, it is beneficial if it analyzes the alternatives and creates a more performant or efficient plan. In the design process based on the problem-solving approach, AI will play a role as a supporting tool for the creation of newer alternatives. In doing so, the architect can broaden the breadth of thought by calculating and presenting unexpected forms that the architect did not think of. Given the repetitive learning and reasoning ability of AI, these two supports are expected to be possible. However, the abstract targeting and various models of architecture increase the difficulty of introducing AI[7][8].

\subsection{Examples of Applying Artificial Intelligence to Architectural Design}

The recent cases of introducing AI to architectural design are as follows and can be classified into the field of automatic production using algorithms and the field of suggesting alternatives through performance review.

In the field of automatic production using algorithms, AI is mainly used in the direction of automatically generating complex shapes. [Fig. 3] (A) is a study to automate the design drawings of reinforced concrete structures using a building information modeling (BIM) library, which minimizes unnecessary work and improves design efficiency[9]. [Fig. 3] (B) is a study on the development of automatically designing a formwork, algorithm, and interface to automatically generate formwork based on the construction frame model[10]. [Fig. 3] (C) is an example of automating product production by inputting the rule of creation as a function installed in commercial software[11].

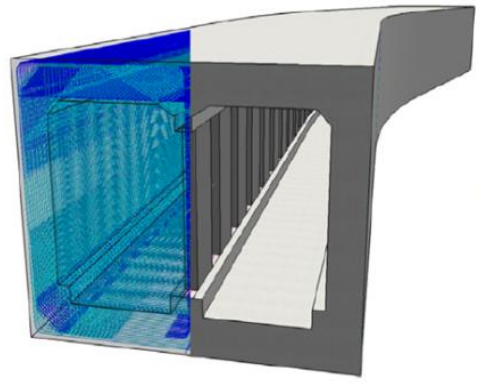

(A)

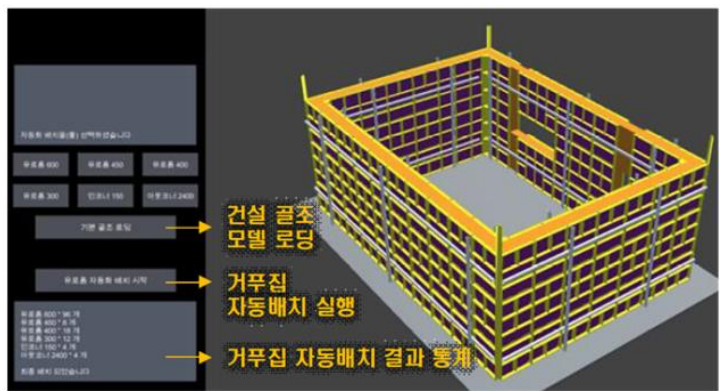

(B)

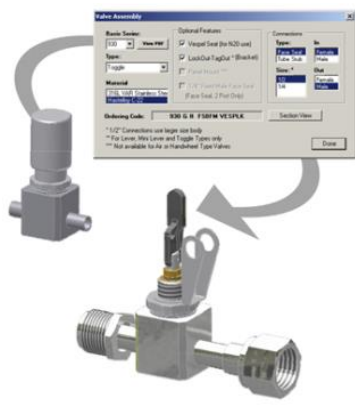

(C)

[Fig. 3] AI in the Field of Automatic Production using Algorithms 


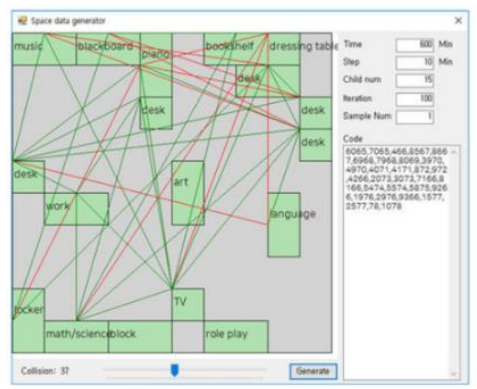

(D)

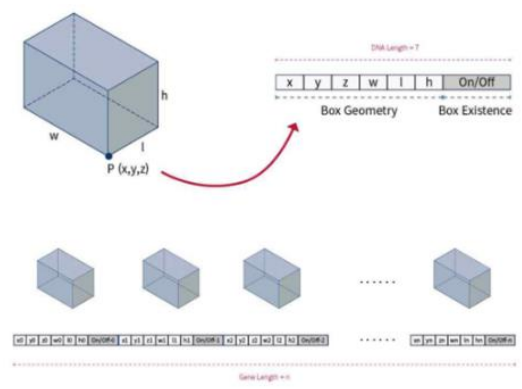

(E)

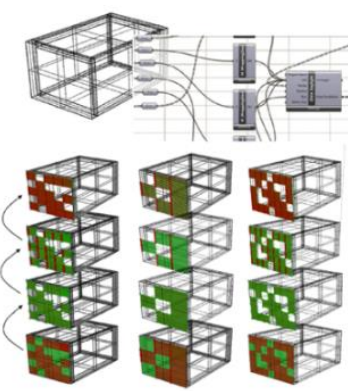

( $F)$

[Fig. 4] AI in the Field of Automatic Production using Algorithms

Research on alternative proposals through performance review, including BIM, has continued since the time BIM appeared in practice, and is accelerating as interest in AI increases[8-10]. As the social demand for so-called performance-based design is high, research using AI to suggest alternatives through performance review is underway. [Fig. 4] (D) is a study on the development of technology to derive the space arrangement of kindergartens by using deep learning technology to optimize the walking safety of kindergarteners[11-13]. [Fig. 4] (E) is a study on technology development to search for the optimal space by analyzing applied building codes using genetic algorithms[1]. [Fig. 4] (F) is a study on a technology that analyzes the eco-friendly performance of the outer shell through an algorithm and presents various alternatives to support the best alternative choice for an architect[14].

\section{Developing a Design Automation Technology Based on the Puzzle-Making Approach}

\subsection{Introduction}

Research related to architectural design using AI, which was recently studied, can be said to correspond to the problem-solving approach in the direction of architectural design, as discussed above. In order to increase the validity of the design and review the performance, this method is very meaningful. However, as discussed, the puzzle-making approach is a method that puts more emphasis on the value of the creative idea of architectural design. This is also an important design method, and if AI is applied, positive results of design results and processes can be obtained.

\subsection{Strategies of Development}

Architects perform architectural design through various architectural design processes. The traditional architectural design process after modern times is shown in [Fig. 5]. In other words, in many cases, the order is Conceptual Design, Schematic Design, Design Development, Construction Documents, and Construction Administration. This is related to modern procedures such as proposal, design, administration, and construction. Also, the process in the design studio of the College of Architecture is similar. Of course, each step does not simply proceed linearly, but a continuous feedback process is involved[15].

When it comes to the initial stage of architectural design, it can be generally referred to as Conceptual Design and Schematic Design. In the conceptual design stage, research and determine the owner's criteria for the project are conducted. At this time, mainly programming, budget analysis, schedule development, code analysis, as-built drawings, site analysis and selection are carried out. In schematic design stage, architects explore design concepts. Present options and narrow down to one 
preferred concept is achieved. At this time, site plans, floor plans, key elevations, key sections, area analysis, renderings or models, and preliminary costs are implemented. These two processes are very important in the architectural design process. Because many of the most creative ideas can happen. Also, since the big picture of the building is determined, it is a stage in which experienced architects play an important role. This study aims to develop design automation technology for the early stages of architectural design, where the most creative activities are likely to occur in the architectural design process.

[Fig. 6] shows the stage of mass study in the architectural design process. Traditionally, mass studies have played a very significant role in the architectural design process. Through the mass study process, the overall shape of a building is devised, and laws and architectural meanings are generally reviewed. The overall design direction of a building is a process in which many parts are determined. Most of this process is carried out in the early stages of architectural design, and since this is the process in which the greatest number of cases occurs, it is the most appropriate stage for the creativity of the architect to be expressed[16].

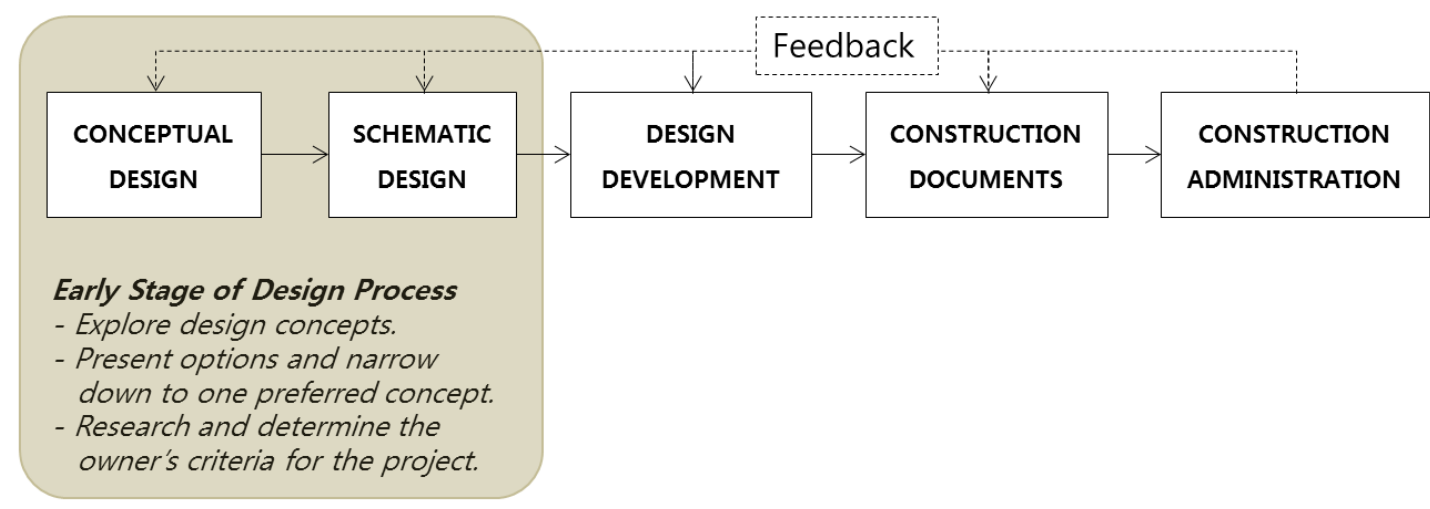

[Fig. 5] Traditional Architectural Design Process \& The Characteristics of the Early Stage of it

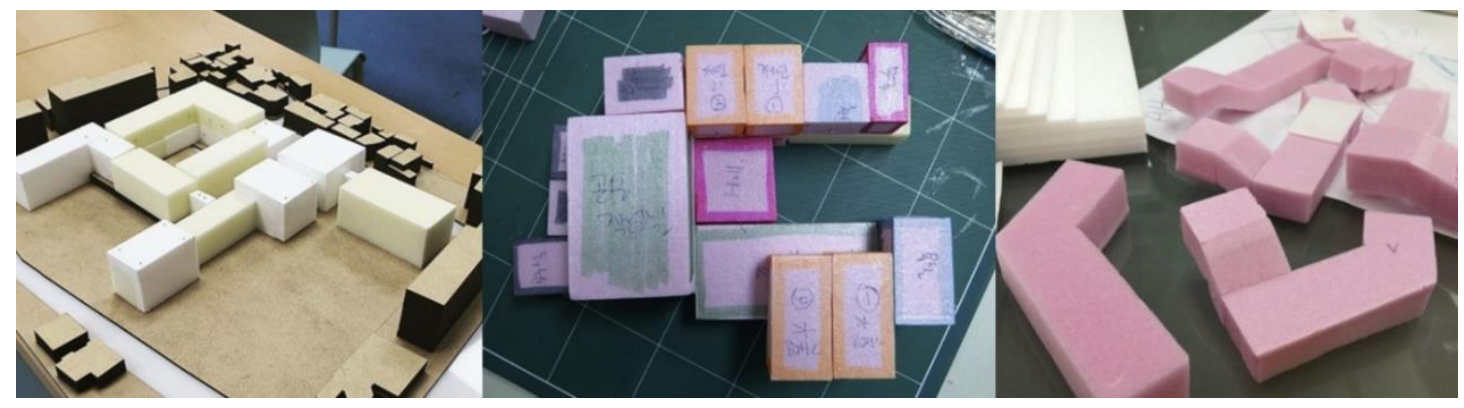

[Fig. 6] Mass Study in the Architectural Design Process

In this study, we intend to develop a technology that supports the creation of creative alternatives for architects by utilizing AI in the mass study process, which is the stage with the highest possibility of expressing creativity. This can be seen as technically realized through AI, in line with the architectural approach of Christopher Alexander and Peter Eisenman.

\subsection{System Design and Development}

In this study, it is essential that target automated planar alternative generation technology is operated in close contact with the design process. Therefore, development was carried out based on SketchUp, a commercial design tool widely used in design practice. [Fig. 7] shows the appearance and execution process of the floor plan generator (FPG) developed through this study. Draw a plane in SketchUp, 
select it, and run the developed FPG from the menu that runs the external module of SketchUp. Then, as shown in the [Fig. 7], the FPG is executed randomly creates a room shape and combines it to create a flat mass shape. By repeatedly performing this method, countless plane combinations can be created. [Fig. 8] shows a plan view created by the FPG through a mass study in minutes.

For this development, using a software development kit (SDK) provided by SketchUp, the designed shapes can be called and external modules can be executed. Based on C\#, the FPG interface and a 2D plane drawing function can be developed. Unity3D, a game engine, was used to perform tasks similar to mass studies, and it was developed in a way that randomly created and combined masses in a 3D game space. Similar to the architectural design process, several masses are created in consideration of the size of the site, and the plan form was created by twisting them back and forth[17].

\subsection{System Test and Results}

By utilizing the rigid body dynamics function, which is widely used in game development, the generated masses are configured to be arranged naturally without overlapping, and parts of the mass are cut out of the boundary of the site so they can settle on the site. The part where one mass meets another mass is configured to be recognized as an opening. This method is very similar to the way in which mass studies are conducted in actual architectural design. [Fig. 7] shows the planes created within a few minutes, and it can be seen that various planes that are difficult for architects to devise with experience or imagination are being created.

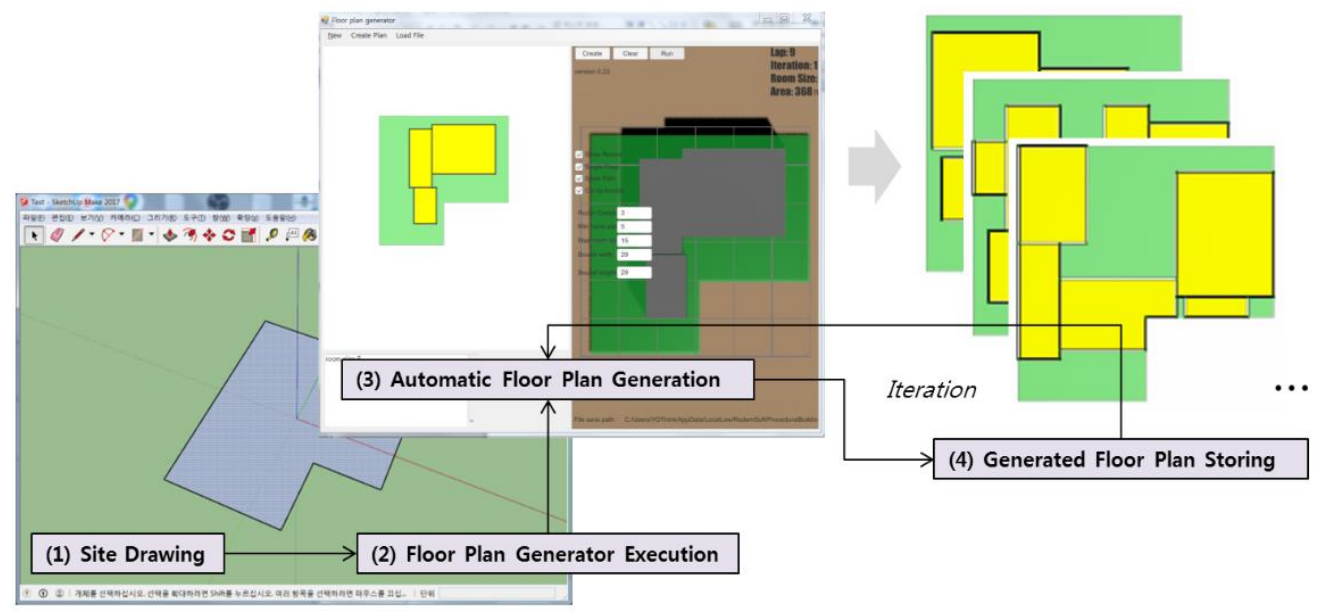

[Fig. 7] The Shape and Execution Process of the Developed FPG

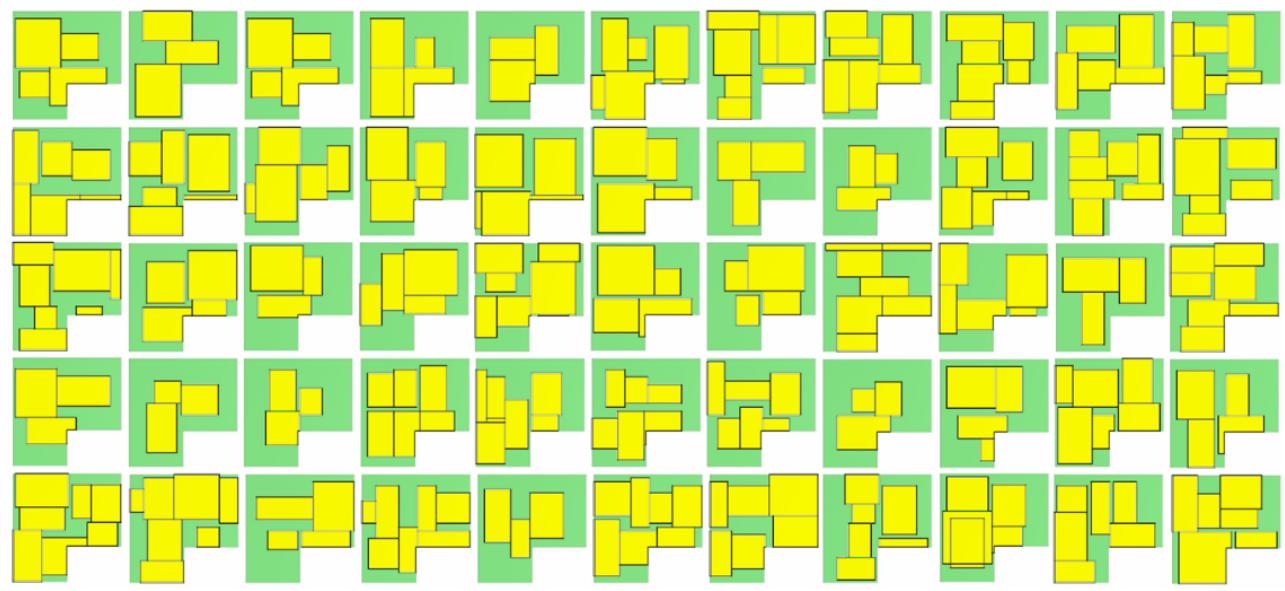

[Fig. 8] Examples of planes created by the FPG (green = ground, yellow = floor space) 


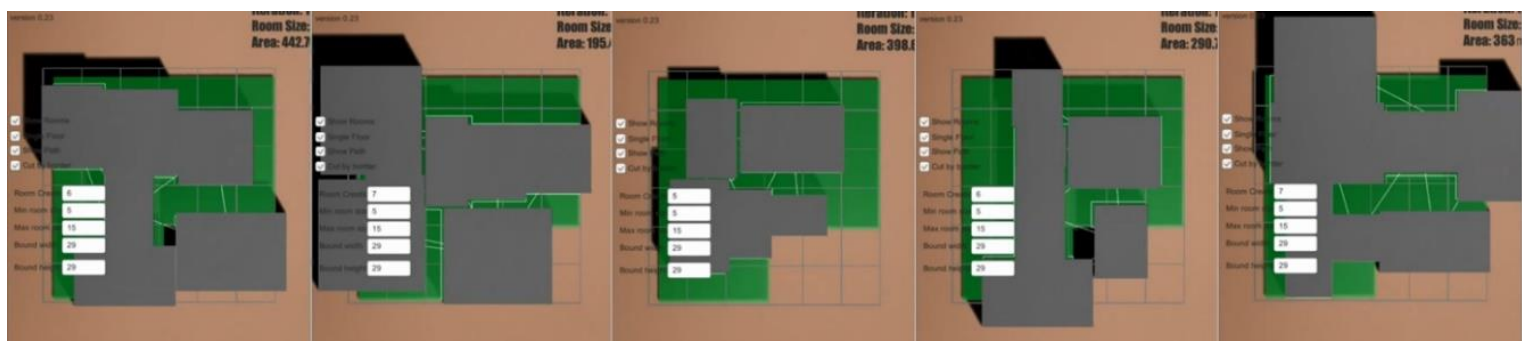

[Fig. 9] Automatic generation and deployment of masses in FPG

\subsection{Findings and Implications}
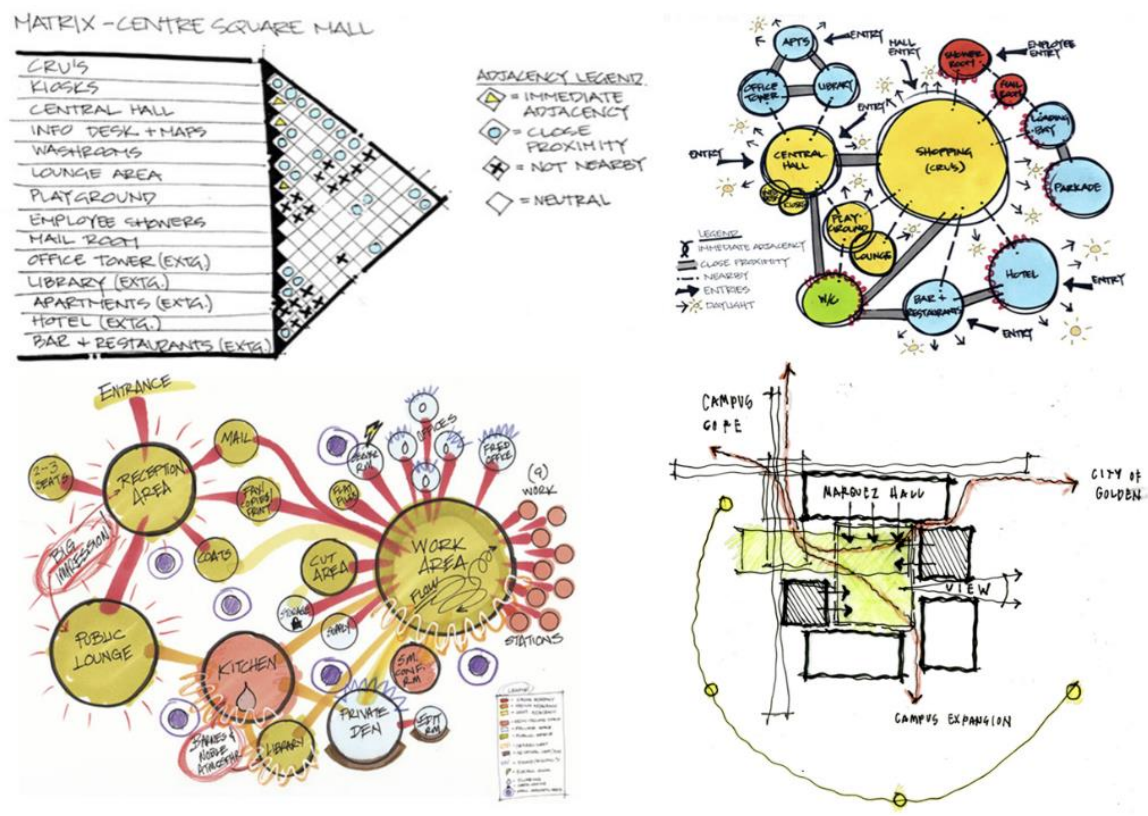

[Fig. 10] Design performance review diagram at the mass-study stage (position, scale, adjacency, sun position, field of view, external space, etc.)[18-20]

[Fig. 9] shows that masses are automatically created and placed on the FPG, and at the same time, mass adjacencies are established. In this study, this function is used to the extent that only their adjacency relationship is set, but in the future, it can be used to evaluate the performance of the alternative created through it. The possibility of the performance evaluation of the plane created based on FPG can be seen through [Fig. 10], which shows the evaluation method of the design through diagram. This method is used in the early stages of architectural design along with mass studies and is used as a method to evaluate the overall design. Observing [Fig. 10], it can be seen that the main direction of evaluation is for each room and the relationship between each room and the surrounding situation. The evaluation of the room is size, location, use, etc. Relationships include the relationship to each room, the relationship between the room and the outside space, etc. This can be said to be linked to the functions generated by the FPG developed through this study. In other words, in FPG, the creation of automatic masses, arrangements, and connections are the basis to which traditional design evaluation methods can be applied[21].

\section{Conclusion \& Discussion}

This study aims to develop technology to introduce AI in the mass study process, which is the initial 
stage of architectural design and is related to the technology development that automatically generates various planes. This study explored the possibility of introducing artificial intelligence in the early stages of design through technology development. The developed technology utilizes physics engines used in games to reproduce the mass-study process, similar to the phenomena occurring in the actual architectural design in the system. Based on this, it can create various types of planes that the architect cannot or could not think of themselves. This is meaningful in that it can act as a base technology that supports more creative design activities in the early stages of architecture. In addition, it is possible to support more efficient design work by significantly saving time and effort in the initial design process. As a result of testing through the developed system, it was found that the introduction of artificial intelligence in the early stages of construction can support the creative design activities of architects through the creation of various planes. However, since the developed system does not perform performance evaluation along with the creation of various planes, there is a limitation that is not completely consistent with the design method in the early stages of construction.

To overcome the limitation of this research, this study needs several improvements or additional studies as follows. First, traditionally, in the mass-study process, there is a process of evaluating the drafted plan based on the architect's experience or the laws of the surrounding area, and this needs to be considered. Second, the mass study is made in three dimensions and is considered for a double layer, which requires additional development. Third, it is necessary to develop a technology that allows for mass-type data derived in the early stages of design to be naturally connected to the architectural process.

\section{Acknowledgments}

This research was supported by the Academic Research Fund of Hoseo University in 2019 (20190834).

\section{References}

[1] Y. G. Lee, A Study on the Application of Deep Learning for Automatic Alternative Placement of Nursery Area , Asiapacific Journal of Multimedia Services Convergent with Art, Humanities, and Sociology, (2019), Vol.9, No.2, pp.813-821, DOI : 10.35873/ajmahs.2019.9.2.079

[2] Y. Bengio, A. Courville, P. Vincent, Representation Learning: A Review and New Perspectives, IEEE Trans. PAMI, (2013), Vol.35, No.8, pp.1798-1828, DOI:10.1109/TPAMI.2013.50

[3] G. Hinton, Li Deng, D. Yu, G. Dahl, Abdel-rahman Mohamed, N. Jaitly, A. Senior, V. Vanhoucke, P. Nguyen, T. Sainath, B. Kingsbury, Deep Neural Networks for Acoustic Modeling in Speech Recognition: The Shared Views of Four Research Groups, IEEE Signal Processing Magazine, (2012), Vol.29, No.6, pp. 82-97, DOI: 10.1109/MSP.2012.2205597

[4] C. Alexander, S. Ishikawa, M. Silverstein, A pattern language, Oxford University Press, (1977)

[5] H. Han, J. H. Lee, A Study on the Speculative Process of a House Design Based on the Analysis of HOUS X of Peter Eisenman, Journal of the Architectural Institute of Korea-Planning \& Design, (1999), Vol.15, No.12, pp.125-134.

[6] J. Archea, Puzzle-making: What Architects Do When No One is Looking, Principles of Computer-aided Design: Computability of Design, Wiley-Interscience New York, USA, (1987), pp.37-52.

[7] D. Kim, Deep Learning Neural Networks for Automatic Vehicle Incident Detection, Asia-pacific Journal of Convergent Research Interchange, (2018), Vol.4, No.3, pp.107-117, http://dx.doi.org/10.14257/apjcri.2018.09.11

[8] Lei Li, An Extensive Review on Recent Deep Learning Applications, Asia-pacific Journal of Convergent Research Interchange, (2019), Vol.5, No.3, pp.221-231, http://dx.doi.org/10.21742/apjcri.2019.09.22 
[9] S. Y. Park, D. Y. Lee, S. W. Kim, S. B. Lee, Study on Automation of Design Drawing of Reinforced Concrete Structure Using BIM Library, Proceedings of Korean Society of Civil Engineering Conference, pp.1278-1280, (2019),

[10] B. K. Lee, T. H. Lee, J. S. Kim, D. E. Lee, H. G. Choi, A Study on the Development of 3D Software for Automated Formwork Design, Proceedings of the Korea Institute of Building Construction Conference, The Korean Institute of Building Construction, Vol.19, No.2, pp.112-123, October 31st to November 1st, (2019), Seoul, Korea

[11] https://knowledge.autodesk.com/support/inventor, Jan 10 (2021)

[12] I. H. Kim, OpenBIM based Automated Building Code Compliance Checking System, Architecture, (2019), Vol.63, No.6, pp.29-31.

[13] J. M. Lee, J. W. Jung, A Study of Automation of Housing Design Method Using Artificial Intelligence - Optimal Space Exploration with Genetic Algorithm Based on Building Codes, Proceedings of the Architectural Institute of Korea Conference, (2019), Vol. 39, No. 2, pp.181-184.

[14] D. Y. Kim, S. A. Kim, An Integrated Design Process of Climate Adaptive Building Shells using Generative Algorithm, Journal of the Architectural Institute of Korea-Planning \& Design, (2014), Vol.30, No.3, pp.23-30.

[15] https://hmhai.com/design-phases, Jan 10 (2021)

[16] G. Goldschmidt, Chapter 9 - Visual Analogy - a Strategy for Design Reasoning and Learning, Design Knowing and Learning: Cognition in Design Education, Elsevier, (2001) pp.199-219, https://doi.org/10.1016/B978-0080438689/50009-7

[17] J. Kim, R. Ryu, Y. Kim, A Basic Study on Unit Module Planning for the Design Diversity of Modular Architecture, Asia-pacific Journal of Convergent Research Interchange, (2019), Vol.5, No.1, pp.31-45.

[18] https://www.behance.net/gallery/3560881/Thesis-Centre-Square-Mall, Jan 10 (2021)

[19] https:/www.behance.net/gallery/5291297/Corporate-Interior-Remodel-Big-River-Advertising, Jan 10 (2021)

[20]https://www.archdaily.com/884244/marquez-hall-at-colorado-school-of-mines-bohlin-cywinski-jackson-plusanderson-mason-dale-architects/5a175e2fb22e38d3f4000008-marquez-hall-at-colorado-school-of-mines-bohlincywinski-jackson-plus-anderson-mason-dale-architects-diagram, Jan 10 (2021)

[21] B. Kam, Automatic Generation of Author Output based on the Iterative Clustering Method, Asia-pacific Journal of Convergent Research Interchange, (2020), Vol.6, No.5, pp. 25-33. 